\title{
Intraoperative Localization of Intracranial Lesions with Real Time Ultrasound
}

\author{
Michael C. Boyd, Paul Steinbok, Peter L. Cooperberg
}

\begin{abstract}
High resolution ultrasound has been used intraoperatively on forty-five patients with various intracranial lesions. The technique is quickly and easily carried out under sterile conditions in the operating room. Successful localization of both primary and metastatic tumors of various sizes, depths and consistencies have been made prior to extirpation or biopsy. Several of the biopsies were done through small burr holes. Arteriovenous malformations, abscesses, bone fragments from trauma, gliotic epileptic foci and ventricles for shunt placement have been readily found. No significant complications have been encountered. A new technique for localizing superficial lesions is described. An overall reduction in operating time and unnecessary trauma to the patient has resulted from more accurate intraoperative localization of intracranial lesions with real time ultrasound.
\end{abstract}

RÉSUMÉ: Localisation peropératoire avec les ultrasons en temps réel Nous avons utilisé les ultrasons à haute résolution de façon peropératoire chez 45 patients avec des lésions intra-crâniennes diverses. Cette technique s'accomplit facilement et rapidement sous des conditions stériles dans la salle d'opération. Nous avons réussi la localisation de tumeurs primaires ou métastatiques de diverses grosseurs, profondeurs et consistances et ce avant l'extirpation ou la biopsie. Plusieurs biopsies furent faites au travers de petits trous de trépan. Nous n'avons éprouvé aucune difficulté à trouver des malformations artérioveineuses, des abcès, des fragments osseux secondaires à des traumatismes, des foyers épileptiques gliosés et les ventricules pour dérivations opératoires. Nous n'avons pas eu de complications significatives. Nous décrivons aussi une nouvelle technique pour localiser les lésions superficielles. Nous constatons que l'emploi de cette procédure a résulté en une réduction globale du temps opératoire et des traumatismes non nécessaires.

Can. J. Neurol. Sci. 1985; 12: $31-34$

With the advent of CT scanning preoperative localization of intracranial lesions has significantly improved. However, intraoperative localization of some lesions when they lie below the cortical surface often presents a frustrating problem to the neurosurgeon. Free hand attempts at obtaining biopsies of deep tumors may be dangerous as well as unsuccessful. Recently, computer tomographic (CT) compatible stereotactic frames, which allow accurate placement of biopsy needles into deep seated lesions in critical areas, have become available (Apuzzo and Sabshin, 1983). However this may be a very time-consuming procedure and should not be necessary in most cases. Within the last few years real time ultrasonography has been adapted for intraoperative use under sterile conditions. Most brain lesions have different echogenicity from the surrounding normal brain and, therefore, are easily localized with ultrasound. Several authors have recently described this technique (Chandler et al., 1982; Dohrmann and Rubin, 1981; Grade and Kumaika, 1983; Sjolander et al., 1983; Voorhies et al., 1983).

The technique is simple and requires no preparation. Successful results are immediately evident by "visualizing" the biopsy needle or its tract entering the lesion. In addition, it has also been found useful in defining the ventricles for insertion of catheters (Merritt et al., 1983), mass lesions prior to attempted removal (Longe et al., 1982), bone fragments from trauma (Enzmannetal., 1981), the extent of arteriovenous malformations (Rubin and Dohrmann, 1983) and more recently, even aneurysms (Hyodoet al., 1983). Complications related to the use of ultrasound have not been a problem (Chandler et al., 1982; Merritt et al., 1983; Tsutsumi et al., 1982).

\section{METHOD}

Preparation for the use of the ultrasound machine (advanced technology labs ATL/ADR acorn tip 3.0 or 5.5MHZ mechanical sector transducer) is made by opening the calvarium with a standard burr hole, trephination or craniotomy. Once the dura has been exposed, the ultrasound probe is covered with a sterile glove which has had acoustic coupling gel squeezed into it. The cord leading to the display unit is covered with a sterile sleeve and the surgeon is then free to manipulate the probe as he pleases.

In most cases, the probe may be placed directly over the dura or pia mater using saline for acoustic coupling. If, however, the lesion proves to be too superficial for the focal zone of the 
transducer, a sterile glove filled with water may be placed over the bony defect to act as an acoustic standoff.

The surgeon is then able to scan in any direction he wishes. The lesion is found and its relationship to other intracranial structures such as the ventricles, falx cerebri, tentorium or choroid plexus is identified. A needle may be passed into the lesion under direct "vision" with the transducer held in place (Dohrmann and Rubin, 1981), or by the memory technique in which the operator replaces the probe with a biopsy needle held at the same angle. In the former, the needle can be seen going directly into the lesion. In the latter, the tract left by the needle can usually be seen after the needle has been removed. Ventricular catheters can easily be checked for position within the ventricles.

Occasionally it is difficult to orient oneself within the brain in relationship to the ultrasound display. However, with experience and the aid of the ultrasonologist this usually becomes less of a problem. Should hemorrhage occur within the brain substance, its focus can be quickly localized and a direct and immediate approach made to controlling it.

\section{Patients}

Included in this series are 45 patients, all of whom had pathological lesions localized preoperatively by a CT scan. Twenty-nine had craniotomy openings, while twelve had burr holes, three had trephinations and one had a laminectomy. Although 33 lesions were initially visualized with the probe placed on the dura and 12 with it placed directly on the pia mater, either method is acceptable. There were 18 cases in which a biopsy was the sole procedure and 25 in which total removal of a lesion was attempted after localization. Two cases involved simply cyst drainage and one required ventricular localization for catheter placement. In each case the intraoperative ultrasound scan was compared to the preoperative CT scan for size, depth and consistency of the lesion. Success of the procedure was determined by whether or not an adequate tissue sample was obtained or the cavity catheterized, and by how many needle passes were required for completion.

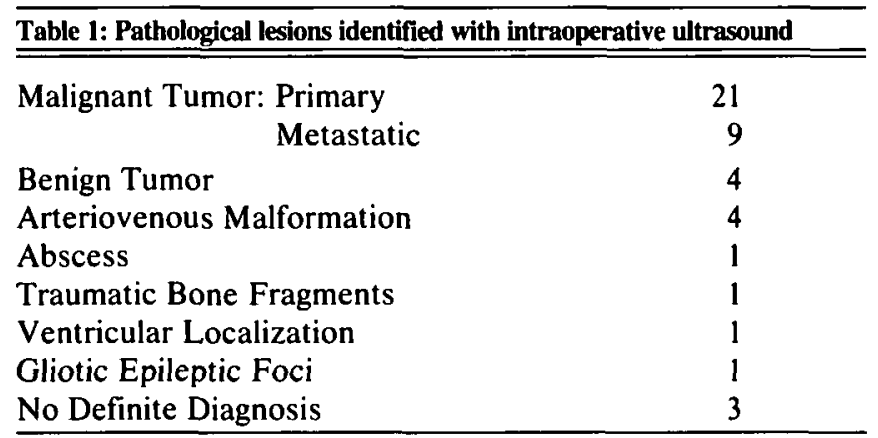

\section{Results}

The various pathological lesions are shown in Table 1. Most of the procedures were done for neoplastic lesions (Fig. 1, 2). However, there were four arteriovenous malformations, all of which had previously hemorrhaged. One abscess was drained. In one case of a bullet wound to the head, ultrasound was used to find residual bone fragments. The consistency of the lesions correlated well with that seen on CT scan. Cystic or fluid filled cavities were easily visualized, as were calcifications within a lesion. The dense ring enhancement from hypervascularity around a less dense core, typically seen in many tumors on contrast enhancement $\mathrm{CT}$, showed a similar picture on ultrasound. There was not a consistent difference in size of masses as measured by the two techniques.

The depth of the lesion within the brain compared favourably between ultrasound and CT. A problem arose, however, when the mass was very superficial, lying just below the cortical surface. In such cases, the low frequency (3.0MHZ) probe could not visualize the lesion due to poor near field focusing. This problem may be circumvented either by changing to a higher frequency (5.5MHZ) transducer head with better focusing in the near field, or by interposing a water bag or phantom between the transducer and brain surface. The latter technique artifically places the lesion in the focal zone of the lower frequency transducer (Fig. 3).

We had five cases in our series which caused some problems. Prior to the use of the water phantom technique described above, three very superficial lesions were not seen. Presumably, this would not happen now.

In a fourth case, the lesion was well visualized with the ultrasound and the biopsy needle was seen to pass into its substance, however, a pathological diagnosis could not be made on the tissue obtained. In a fifth case, although the exact lesion could not be located, identification of the lateral ventricle and calcified choroid plexus and their relationship to the lesion on the CT scan permitted accurate enough positioning of the biopsy needle to obtain diagnostic tissue on a single pass.

On the average in biopsy cases, an adequate specimen was obtained on one or occassionally two needle passes. Only two cases required three passes and one case four passes. There have been no complications directly related to the use of ultrasound.

\section{Discussion}

Ultrasound is ideally suited for identifying structures within the soft tissue of the brain once a window through the dense bone of the skull has been opened. The basic principle of operation involves measuring the time delay and intensity of reflected energy in the form of high frequency ultrasonic signals as they are bounced off tissues of varying densities or echogenicity. Low density substances (cerebral spinal fluid, fat) have poor echogenicity and therefore transmit most of the energy incident upon them. Dense substances (bone, calcium), on the other hand, reflect most of this incident energy. Thus, high density substances such as calcium particles or low density structures such as fluid filled cavities will reflect more or less energy respectively when imbedded in a tissue of medium density such as normal brain. The depth of these structures may be found by plotting the intensity of the reflected energy as a function of time - the more delayed the signal the deeper the structure. In infants ultrasound may be used percutaneously to visualize the intracranial contents as there is no high density bone to block the signal when it is used over the natural window of an open fontonelle.

Ultrasound has been found to be a very useful tool for intraoperative localization of intracranial lesions. Although we have only used it during the initial stages of the operation, others have found it useful in evaluating the completeness of tumor removal and mapping the distribution of residual tumor 
(Rubin and Dohrmann, 1983). It is particularly useful when cystic components are present within the lesion. Indeed, it has been suggested that ultrasound shows loculations even better than CT scan although we did not find this to be necessarily true (Rubin and Dohrmann, 1983).
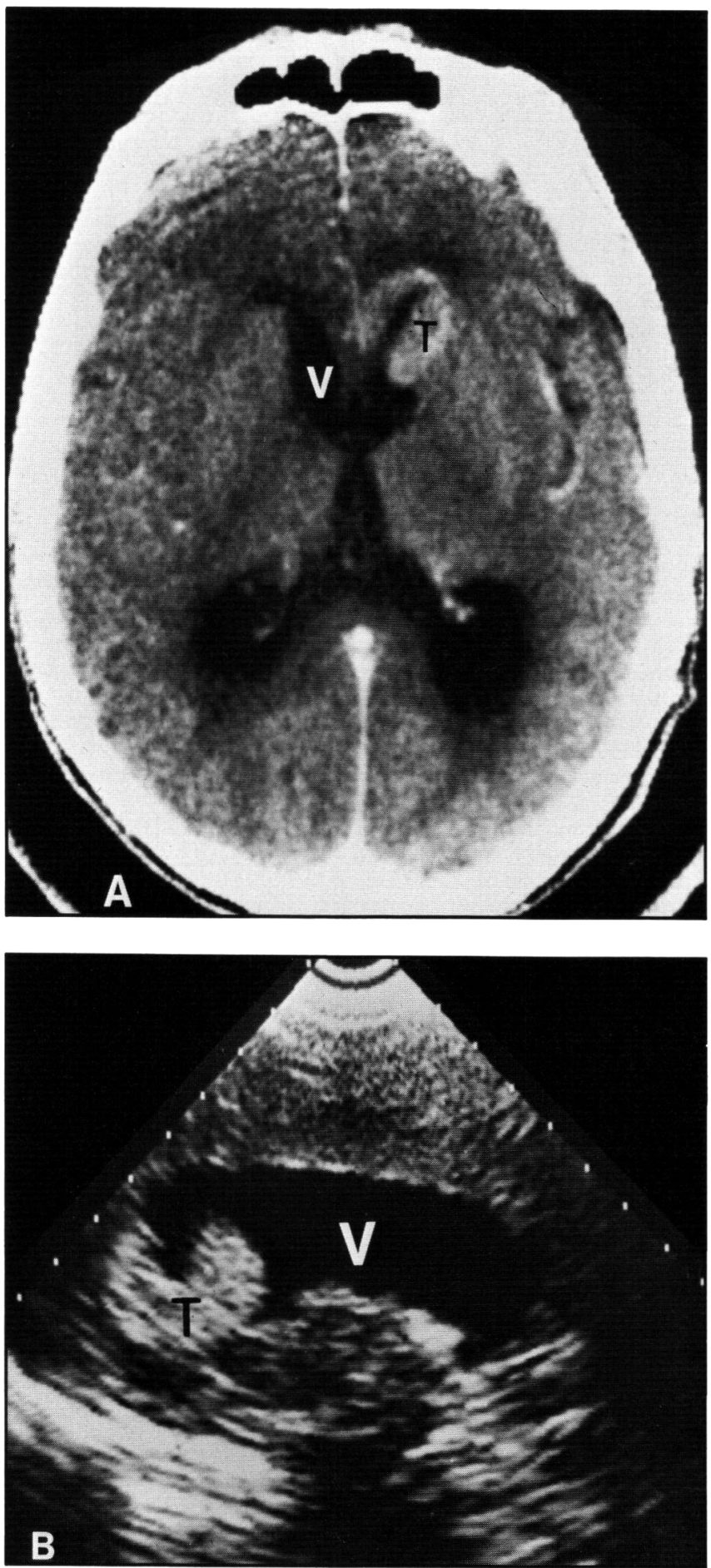

Figure I - (A) Preoperative enhanced CT scan of a metastatic oat cell carcinoma $(T)$ to an anterior horn of the lateral ventricle $(V)$. (B) Intraoperative ultrasonogram (3.OMHZ) of the same lesion as in $(A)$. Cephalad is at the top of the image. frontal is to the left and occipital to the right. $(V=$ ventricle, $F=F a l x)$
Superficial lesions are often very difficult to locate with low frequency ultrasound. Sometimes this problem may be alleviated by using a higher frequency probe that has better near field characteristics. However, an alternative is to artificially increase the distance to the mass by placing a water bag phantom between the transducer and the brain surface. Voorhies et al. (1983) achieved this by damming water over the bony opening. Although he found this technique useful, an absolutely water tight seal was difficult to maintain. The water bag phantom described here alleviates this problem completely. The phantom is virtually transparent to the ultrasound yet the interface between the water and the brain provides a good landmark for estimating the depth of the lesion.

As yet there have been no complications related to the procedure, however, it is possible that some may occur.
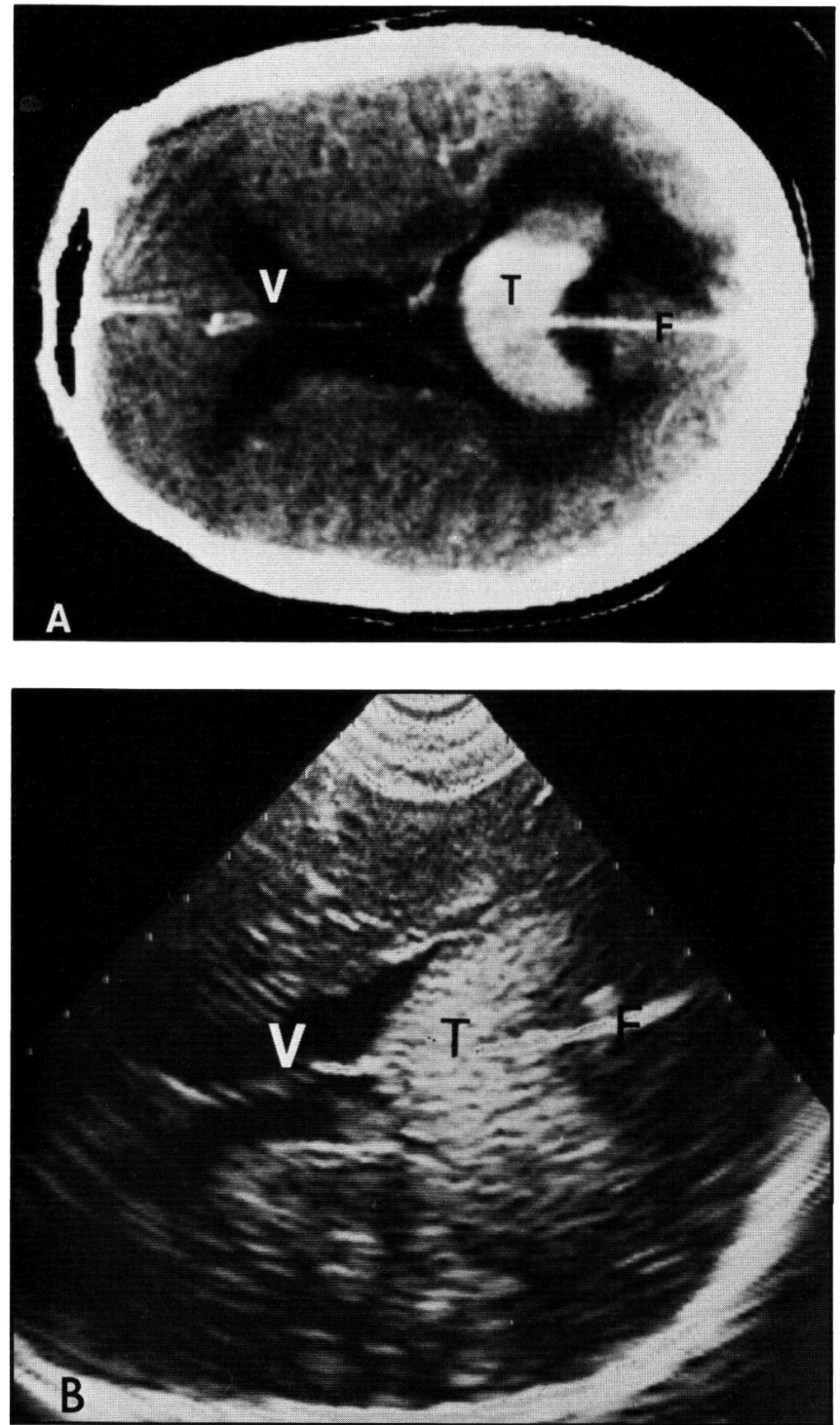

Figure $2-$ (A) Preoperative enhanced CT scan of a glioblastoma multiforme $(T)$ spreading across the splenium of the corpus callosum. (B) Intraoperative ultrasonogram (3.OHMZ) of the same lesion as in $(A)$. The right side of the patient is at the top, frontal is to the left and occipital to the right. $(V=$ ventricle, $F=$ falx $)$ 

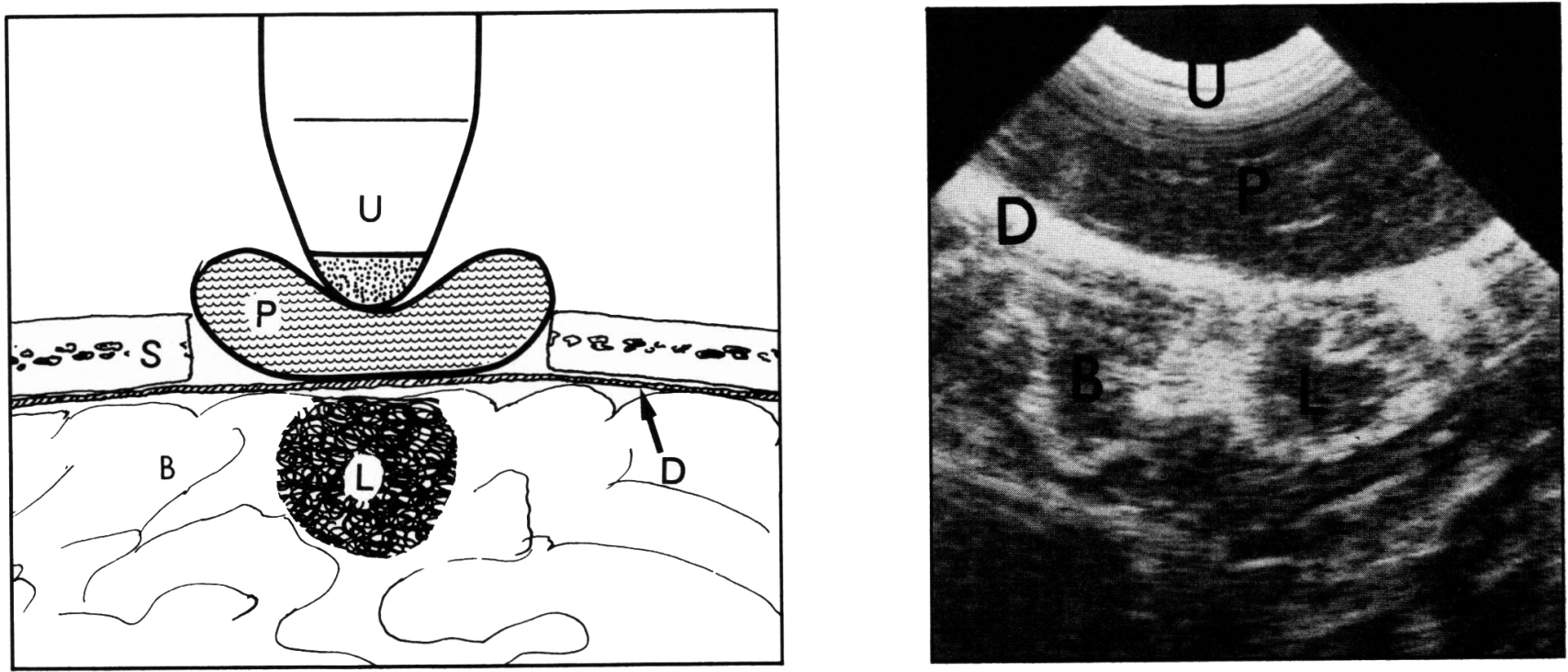

Figure $3-$ Diagramatic representation (left) of an intraoperative ultrasonogram (right) using a water phantom to visualize a superficial AVM $(L) .(U=U \mid$ tirasound Transducer, $P=$ Water Phantom, $D=$ Dura Mater, $B=$ Normal Brain, $S=$ Skull)

Introducing a nonsterile object into the operating field, even though it may be properly draped, increases the risk of infection. Inadvertently pressing too firmly on the brain surface may cause local bruising. Both of these, however, may be minimized, the former by meticulously following strict aseptic procedures, and the latter by applying careful technique and using the probe through the protective covering of dura whenever possible.

The likelihood of obtaining an adequate tissue sample is greatly increased when the biopsy needle is seen to enter directly into the tumor mass. Having the ability to do this on a single pass, as occurred in most cases in our series, certainly negates the chance of causing further damage on repeated attempts. However, should one have the misfortune of causing a significant intracerebral hemorrhage, the ability to quickly recognize and locate the problem with ultrasound can mean a reduction in time needed to bring the bleeding under control.

Our experience to date has shown ultrasound to be a quick, safe and accurate aid in the intraoperative localization of many intracranial lesions.

\section{ACKNOWLEDGEMENTS}

The authors wish to thank Drs. F.A. Durity, G.B. Thompson, I.M. Turnbull, and W,B. Woodhurst for allowing us to use their patients in this series.

\section{REFERENCES}

Apuzzo ML, Sabshin JK (1983) Computed Tomographic Guidance Stereotaxis in the Management of Intracranial Mass Lesions. Neurosurgery, 12: 277-285.
Chandler WF, Knake JE, McGillicuddy, et al (1982) Intraoperative Use of Real Time Ultrasonography in Neurosurgery. J. Neurosurg. 57: 157-163.

Dohrmann GJ, Rubin JM (1981) Use of Ultrasound in Neurosurgical Operations: A Preliminary Report. Surg. Neurol. 16: 362-366.

Enzmann DR, Britt RH, Lyons B, et al (1981) Experimental Study of High Resolution Ultrasound Imaging of Hemorrhages, Bone Fragments and Foreign Bodies in Head Trauma. J. Neurosurg. 54: 304-309.

Grode ML, Komaiko MS (1983) The Role of Intraoperative Ultrasound in Neurosurgery. Neurosurgery, 12: 625-628.

Hyodo Y, Mizukami M, Tazawa T, et al (1983) Intraoperative Use of Real Time Ultrasonography Applied to Aneurysm Surgery. Neurosurgery, 13: 642-645.

Lange SC, Howe JF, Shuman WP, et al (1982) Intraoperative Ultrasound Detection of Metastatic Tumors in the Central Cortex. Neurosurgery, 11: 219-212.

Merritt CRB, Coulon R, Connolly E (1983) Intraoperative Neurosurgical Ultrasound. Transdural and Transfontanelle Applications. Radiology, 148: 513-517.

Rubin JM, Dohrmann GJ (1983) Intraoperative Neurosurgical Ultrasound in the Localization and Characterization of Intracranial Masses. Radiology, 148: 519-524.

Sjolander U, Lindgren PG, Hugosson R (1983) Ultrasound Sector Scanning for the Localization and Biopsy of Intracranial Lesions. J. Neurosurg. 58: 7-10.

Tsutsumi Y, Andoh Y, Inoue N (1982) Ultrasound Guided Biopsy for Deep-Seated Tumors. J. Neurosurg. 57: 164-167.

Voorhies RM, Engel I, Gamache FW, et al (1983) Intraoperative Localization of Subcortical Brain Tumors: Further Experience with B-Mode Real Time Sector Scanning. Neurosurgery, 12: 189-194. 